\title{
Morphological response of the leaf blades of $B$. pendula Roth. to the influence of man-made environmental factors
}

\author{
Uliana Semak $^{1, *}$ \\ ${ }^{1}$ Vasyl Stefanyk Precarpathian National University, Department of Biology and Ecology, Halytska \\ str. 201, 76000 Ivano-Frankivsk, Ukraine
}

\begin{abstract}
Due to the technogenic transformation of ecotopes of ash and slag dumps of Burshtyn TPP, bioindications of the environment state in the zone of their influence are an urgent issue. The morphological reaction of Betula pendula Roth. leaves under the influence of man-caused factors of Burshtyn TPP ash and slag dumps was studied. The change in the shape of the leaf blades of $B$. pendula under the conditions of ash and slag dumps was analysed. The degree of modification of leaf blades was evaluated through the measures of shape coefficient and elongation coefficient. The use of morphological coefficients testified to their specificity. The form coefficient indicator proved to be a sensitive marker. The change in the area of leaf blades under the conditions of high levels of anthropopression was analyzed. On the territory of ash and slag dumps there was a decrease of leaf area. At the same time, a high level of necrotization of leaf blades was recorded. The condition of plants was assessed through the index of fluctuating asymmetry of $B$. pendula leaf blades. As a result of the study, the foliar morphometric parameters of $B$. pendula were determined, which showed high morphological reactivity under the influence of man-caused load and can be used as bioindication markers for assessing the state of the environment.
\end{abstract}

\section{Introduction}

The processes of technogenesis lead to a large-scale transformation of ecosystems. This trend needs to be controlled and monitored. A reliable and informative method to assess the impact of factors of man-made influence on living organisms is a bioindication approach. A particularly promising area of bioindication research is phytoindication, which involves the diagnosis of the state of ecosystems by the plant component of these ecosystems.

The objects of bioindication research can be morphological rearrangements of the plant organism, which are recorded under the influence of man-made environmental factors. One of the most informative methods of the integrated assessment of environmental quality based on morphological features of plants is the indicator of fluctuating asymmetry.

Other methods of assessing the state of the environment by morphological features are also convenient tools for bioindication and require further testing.

\footnotetext{
*Corresponding author: ulianasemak@gmail.com
} 
In particular, the variability of morphological parameters as a bioindication indicator, due to the ambiguity of the results, requires further testing.

The purpose of this research is to study the state of plant organisms, namely trees on the territory of the ash and slag dumps of Burshtyn TPP. The study of morphological features, namely the state of the leaf blade, will reflect the level of plants damage in the ecosystem of ash and slag dumps and diagnose the state of the environment.

\section{Theory}

Ash and slag dumps of Burshtyn TPP are special hydraulic structures designed for the accumulation of solid waste from coal combustion. Storage of ash and slag waste causes a number of environmental problems, transformation of natural geochemical cycles, change of natural radioactive background due to increased concentration of radioactive isotopes in coal combustion products $[10,11]$. Weathering and scattering of solid particles of different degrees of dispersion from the surface of the bowls of ash and slag dumps causes aerotechnogenic pollution. Due to the ingress of ash and slag materials from the bowls of ash dumps into surface and groundwater, there is a change in their chemical parameters. The influence of pollutants affects the state of the phytobiota on the area of influence of the enterprise [11].

The most informative object of bioindication research is the assimilation apparatus, which reflects the functional state of the plant organism. One of the phytoindication methods is the indication of environmental conditions by the variability of morphological parameters. It is believed that under conditions of man-made load variability of morphological parameters increases. However, according to modern research $[17,20]$ the level of variability of individual foliar indicators is lower under the conditions of mancaused loading, while other indicators show higher levels of variability under the conditions of man-caused load in comparison with the background territory.

An integral indicator of the morphological response of the assimilation apparatus to man-made load is the fluctuating asymmetry. The increase on the level of fluctuating asymmetry under stress is presented in a number of modern studies [2, 8, 16, 17]. In previous studies, we [18] analyzed the level of fluctuating asymmetry of leaf blades of the three most common species on the study area, in particular $B$. pendula. In all studied species an increase in the indicator of fluctuating asymmetry was recorded, which indicates a violation of the stability of the development of plant organisms and an unfavorable ecological situation on the ash and slag dumps of Burshtyn TPP. However, some studies indicate no increase in asymmetry under stress [5, 15].

Therefore, modern bioindication research is faced with the task of finding new morphological diagnostic indicators to assess the state of the environment under man-made pressure. We propose to determine the indicators of fluctuating asymmetry by measuring the area of the right and left halves of the leaf blade. We consider such approach more convenient in comparison with linear measurements of parameters.

The main modifications of the assimilation apparatus in the technogenic environment are the reduction of morphometric sizes of leaves, changes in their shape, chlorosis and necrosis, as well as wilting of leaves, its fall [3, 6, 8-9, 13-14].

These morphological modifications are the result of acute and chronic exposure to phytotoxicants and can be used as indicative features of plant organisms in a technogenictransformed environment. The area of the leaves is an informative indicator of the state of the plant organism [6,19], because the leaves have the highest accumulative capacity against phytotoxicants. Inhibition of growth processes and reduction of the area of leaf blades are directly dependent on the degree of contamination [6]. 
Occurrence of necrosis and chlorosis is a consequence of excessive contamination with phytotoxic compounds and indicates a crisis in the plant organism.

\section{Methods}

B. pendula was selected as an experimental species that meets the requirements for bioindicator species and has been used in a number of bioindication studies $[2,4,12,16]$. During the research, the morphological features of the leaf blades of the experimental species were studied. We compared the morphological reactivity on the industrial sites of thermal power plants and under the conditions of the protected area (Galician National Nature Park). Leaf selection was carried out according to generally accepted methods, the sample size was 250 leaves for each of the studied species.

The leaves were digitized and the CoralDRAW X6 program was used to measure: 1 length of leafstalk, cm; 2 - leaf length, $\mathrm{cm} ; 3$ - width of the right and left parts of the leaf blade, $\mathrm{cm} ; 4$ - the length of the first one from the edge of the leaf vein on the right and left sides of the leaf blade, $\mathrm{cm} ; 5$ - the length of the second one from the edge of the leaf vein on the right and left sides, cm; 6 - distance between the first and second vein, $\mathrm{cm} ; 7$ - the angle between the central and the first ones from the edge of the leaf blade vein; 8 - the angle between the central and the second ones from the edge of the leaf vein; 9 - leaf area, $\mathrm{cm}^{2}$.

The elongation coefficient (KL) was defined as the ratio of a length of the leaf blade to its width [3]. The calculation of the shape coefficient (KF) of the leaf blade was performed by dividing the leaf blade by a cross section at the level of half and calculated the value of $\mathrm{KF}$ as the ratio of the area of the upper part to the lower one [3].

The index of fluctuating asymmetry was defined as the ratio of the modulus of the difference of measurements on the left and right sides of the leaf blade to their sum:

$$
K=|L-R| /|L+R|,
$$

where: $L$ is the value of the measured parameters of the left side of the leaf; $R$ is the value of the parameters of the right side of the leaf.

Biometric analysis of data was performed by methods of mathematical statistics. The reliability of the obtained results was evaluated using Student's t-test. Statistical processing of morphometric data was performed using the computer program Excel 7.0.

\section{Results and discussion}

The results of this study indicate a difference on the level of variability of foliar parameters of $B$. pendula under the conditions of ash and slag dumps of Burshtyn TPP and in the territory of reference ecosystem. It was found that the modification of foliar parameters under man-made conditions and without of such conditions is not the same.

To assess the morphological variability of the studied parameters, the coefficient of variation was calculated. Most morphological parameters in both monitoring points are characterized by average variability (Table 1$)$.

The most variable feature is the distance between the first and second vein. On the territory of ash and slag dumps the coefficient of variation of the indicator is $32.8-36.3 \%$. However, this feature shows increased variability both at high levels of anthropopression and with minimized exposure to man-made load and in a relatively clean area is 35.9$34.6 \%$. 
Table 1. Variability of morphological indicators Betula pendula Roth: 1 - The territory of reference ecosystem; 2 - the territory of ash and slag dumps of Burshtyn TPP.

\begin{tabular}{|c|c|c|c|c|c|c|c|}
\hline \multirow{3}{*}{ Morphological indicators } & & \multicolumn{6}{|c|}{ Parameters } \\
\hline & & \multicolumn{2}{|c|}{$\mathrm{M} \pm \mathrm{m}$} & \multicolumn{2}{|c|}{$\begin{array}{l}\min \\
\max \end{array}$} & \multicolumn{2}{|c|}{$\mathrm{CV}, \%$} \\
\hline & & 1 & 2 & 1 & 2 & 1 & 2 \\
\hline \multicolumn{2}{|l|}{ The length of leafstalk, cm } & $1,57 \pm$ & $1,56 \pm$ & 1,05 & 0,98 & 21,2 & 15,04 \\
\hline \multirow{3}{*}{\multicolumn{2}{|c|}{ The leaf length, $\mathrm{cm}$}} & & & & & & \\
\hline & & $5,29 \pm$ & $5,22 \pm$ & 0,54 & 3,93 & 148 & 165 \\
\hline & & & & 6,97 & 7,64 & & \\
\hline \multirow{4}{*}{ The width of the leaf, $\mathrm{cm}$} & $\mathrm{L}$ & $1,98 \pm$ & $1,9 \pm$ & 1,5 & 1,19 & 15,7 & 22,9 \\
\hline & & & & 2,6 & & & \\
\hline & $\mathrm{R}$ & $2,0 \pm$ & $1,86 \pm$ & 1,4 & 1,17 & 14.6 & 22.3 \\
\hline & & 0,04 & 0,06 & 2,64 & 2,81 & & \\
\hline \multirow{4}{*}{$\begin{array}{l}\text { The length of the first one from the } \\
\text { edge of the leaf vein on the right and } \\
\text { left sides of the leaf blade, } \mathrm{cm}\end{array}$} & $\mathrm{I}$ & $2,54 \pm$ & $2,51 \pm$ & 1,6 & 1,7 & 1707 & 20 \\
\hline & $\mathrm{L}$ & 0,06 & 0,08 & 3,3 & 0,94 & 17,02 & 22,38 \\
\hline & & $2,58 \pm$ & $2,5 \pm$ & 1,62 & 1,7 & & \\
\hline & $\mathrm{R}$ & 0,06 & 0,09 & 3,5 & 4,08 & 17,8 & 24,73 \\
\hline \multirow{4}{*}{$\begin{array}{l}\text { The length of the second one from } \\
\text { the edge of the leaf vein on the right } \\
\text { and left sides, cm }\end{array}$} & & $2,65 \pm$ & $2,55 \pm$ & 1,77 & 1,7 & 147 & 2404 \\
\hline & L & 0,05 & 0,09 & 3,28 & 3,96 & 14,1 & 24,04 \\
\hline & & $2,65 \pm$ & $2,54 \pm$ & 1,85 & 1,6 & & \\
\hline & $\mathrm{R}$ & 0,06 & 0,09 & 3,29 & 4,24 & 19,08 & 24,9 \\
\hline \multirow{4}{*}{$\begin{array}{l}\text { Disstance betweenthe bases of the } \\
\text { first and second veins, } \mathrm{cm}\end{array}$} & $\mathrm{L}$ & $0,43 \pm$ & $0,53 \pm$ & 0,1 & 0,23 & 35.9 & 32.8 \\
\hline & & & & 0,7 & 0,98 & & \\
\hline & $\mathrm{P}$ & $0,49 \pm$ & $0,51 \pm$ & 0,2 & 0,38 & 346 & 363 \\
\hline & 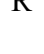 & 0,02 & 0,03 & 0,86 & 0,62 & 34,6 & 30,3 \\
\hline \multirow{4}{*}{$\begin{array}{l}\text { The angle between the main vein and } \\
\text { the first vein from thebase of the leaf }\end{array}$} & $\mathrm{I}$ & 53,69 & $64,4 \pm$ & 38 & 40,6 & 179 & 1703 \\
\hline & $\mathrm{L}$ & $\pm 1,36$ & 1,5 & 79,6 & 87,7 & $1 /, 9$ & $1 /, 00$ \\
\hline & & 54,22 & $64,4 \pm$ & 40,7 & 39,9 & & \\
\hline & $\mathrm{R}$ & $\pm 1,34$ & 1,35 & 75,05 & 80,1 & 17,5 & 14,85 \\
\hline \multirow{4}{*}{$\begin{array}{c}\text { The angle between the main vein and } \\
\text { the second vein from thebase of the } \\
\text { leaf }\end{array}$} & $\mathrm{I}$ & $49,9 \pm$ & $53,5 \pm$ & 30,1 & 40,1 & 121 & 56 \\
\hline & $\mathrm{L}$ & 1,1 & 1,02 & 69,3 & 67,5 & 15,4 & 15,0 \\
\hline & $\mathrm{R}$ & $49,6 \pm$ & 53,63 & 32,1 & 32,3 & 13.8 & 19.8 \\
\hline & & 0,97 & $\pm 1,5$ & 63,6 & 87,5 & & \\
\hline
\end{tabular}

Notes: $\mathrm{M} \pm \mathrm{m}, \mathrm{cm}$ - arithmetic mean; $\mathrm{CV}, \%$ - the coefficient of variation.

The most variable feature is the distance between the first and second vein. On the territory of ash and slag dumps the coefficient of variation of the indicator is $32.8-36.3 \%$. 
However, this feature shows increased variability both at high levels of anthropopression and with minimized exposure to man-made load and in a relatively clean area is 35.9$34.6 \%$.

High level of variability of the leafstalk length in a relatively clean area is $21.2 \%$, in contrast to stressful conditions $-15.04 \%$. The average variable indicator is the length of the first and second veins from the base of the leaf. Under the conditions of ash and slag dumps the coefficient of variation for the length of the first vein is $22.38-24.7 \%$, while in the background $-17.02-17.8 \%$. Regarding the second vein, its variability under stress is 24.04 $24.9 \%$, in the reference area it is $14.7-19.08 \%$.

At the medium and high level in the study areas vary such features as leaf length $(16.5 \%$ and $14.7 \%$, respectively), leaf width $(22.6 \%$ and $15.5 \%)$.

The coefficient of variation for the angles between the central and the first vein processing at the average level is $17.5-17.9 \%$ for the background area and $17.03-14.85 \%$ under stress conditions. The average variable indicator is the angle between the central and other veins and in the reference ecosystem and it is $13.8-13.8 \%$, while on the territory of ash and slag dumps it is $15.6-19.8 \%$.

It should be noted that there is a slight invariance in the display of coefficients of variation with the right and left sides of the leaf blades.

Testing the hypothesis by Student's test showed a significant difference between the choices on the studied marks at $\mathrm{p} \leq 0.05$ (the hypothesis is true to $95 \%$ ).

As a result of the study, the elongation coefficient and the shape coefficient of $B$. pendula leaf blades were calculated. Exceeding of the elongation coefficient of the unit indicates a stable environmental situation. According to the study, the coefficient of elongation of the leaf blades of B. pendula exceeds the unit level (table 2).

Table 2. Morphometric coefficients of $B$. pendula leaf blades.

\begin{tabular}{|l|c|c|}
\hline \multirow{2}{*}{\multicolumn{1}{|c|}{ Indicator }} & \multicolumn{2}{|c|}{ Research area } \\
\cline { 2 - 3 } & $\begin{array}{c}\text { The territory of reference } \\
\text { ecosystem }\end{array}$ & $\begin{array}{c}\text { Ash and slag dumps of Burshtyn } \\
\text { TPP }\end{array}$ \\
\hline Elongation coefficient & 1,3 & 1,25 \\
\hline Shape coefficient & 0,7 & 0,84 \\
\hline
\end{tabular}

The difference under the conditions of the two studied ecotopes on this indicator is insignificant. We studied the change in the shape of the leaf blade. The normal shape of the B. pendula leaf is rhomboid-ovate and triangular-rhombic [1]. The appearance of heartshaped and oval shapes was recorded on the territory of ash and slag dumps. However, in percentage terms, "atypical" forms are a minority $-6.4 \%$. While the typical shape of the leaf - triangular-rhombic predominates $(48.4 \%)$, the rhomboid-shaped form accounts for $45.2 \%$.

The shape coefficient was used to estimate the modification of the leaf blade shape. The shape coefficient, defined as the ratio of the area of the upper and lower half of the leaf blade, for $B$. pendula on the ash and slag dumps is higher by 0.14 , respectively, compared to the territory of reference ecosystem.

This is due to the fact that on the territory of ash and slag dumps there are leaf blades of atypical shape for this species. The change in the shape of the leaf blade causes a higher ratio of the upper and lower parts of the leaf blade in the sample of ash and slag dumps in comparison with the territory of reference ecosystem.

Under the conditions of ash and slag dumps of Burshtyn TPP the decrease of the area of leaf blades of $B$. pendula is observed. The area of leaf blades of the experimental species under stress and in the absence of such is $14.5 \mathrm{~cm}^{2}$ and $15.1 \mathrm{~cm}^{2}$, respectivel. 
The leaves of $B$. pendula trees growing on ash and slag dumps suffer from necrotic lesions. The most common necrosis is on the periphery of the leaf blades. Necrosis occupies approximately $14.1 \%$ of the assimilation surface $\left(2.05 \mathrm{~cm}^{2}\right)$, in the absence of man-made factors $-1.32 \%$ of the assimilation surface (Fig. 1).

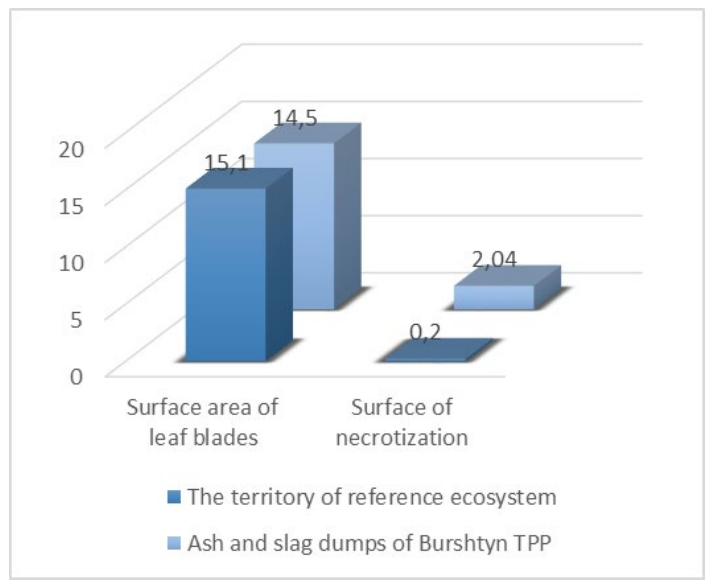

Fig. 1. Assimilation surface area and level of necrotization of leaf blades of B. Pendula, (\%).

During the study, the coefficients of fluctuating asymmetry due to the area of the right and left halves of the leaf blades were determined. According to the results of measurements on the territory of the ash and slag dumps of Burshtyn TPP, the level of fluctuating asymmetry averages 0.052 (Fig. 2). On the territory of the reference ecosystem, the level of fluctuating asymmetry is 0.0348 .

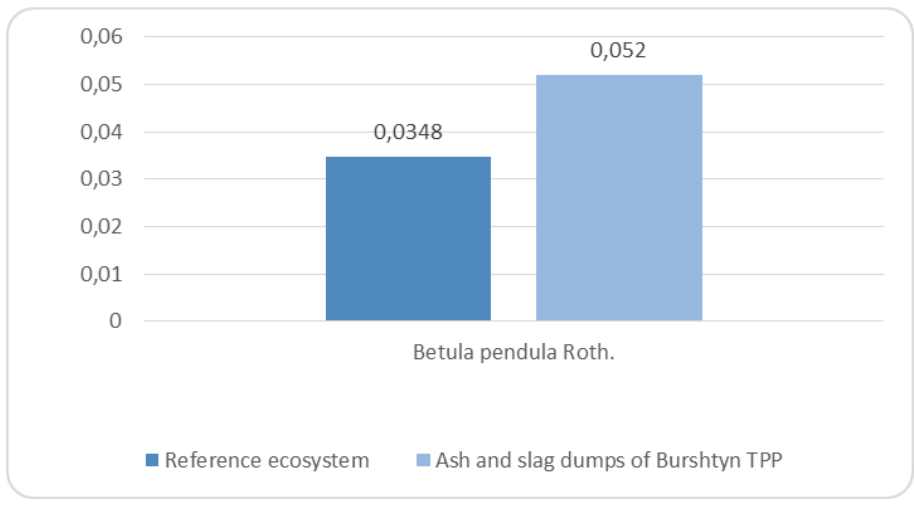

Fig. 2. The level of fluctuating asymmetry of leaf blades of B. Pendula.

Comparative analysis of the morphological reactivity of leaf blades according to the analyzed indicators revealed their different informativeness regarding the indication of high levels of man-caused load.

The results of this study indicate a difference on the level of variability of foliar indicators of $B$. pendula under the conditions of ash and slag dumps of Burshtyn TPP and on the reference territory. Under conditions of man-caused load, most of the analyzed indicators have higher levels of variability. Thus, the detected high variability of the distance between the bases of the first and second veins was observed earlier [20]. The most stable features of the leaf blade of $B$. pendula are the angle between the main vein and the second vein from the base of the leaf, as well as the length of the leafstalk. 
The coefficient of elongation is not recommended for use as a bioindication marker for $B$. pendula. The coefficient of shape of the leaf blade of $B$. pendula is an informative indicator that reflects the change in the shape of the leaf blade under the conditions of high levels of anthropopressing. This is due to the fact that on the territory of ash and slag dumps there are leaf blades of atypical shape for these species. The change in the shape of the leaf blade causes a higher ratio of the upper and lower part of the leaf blade compared to the background area, which is reflected in the ratio of the shape. The use of the value of the area to determine the level of fluctuating asymmetry gives a lower level compared to linear measurements: on ash and slag dumps 0.052 against 0.061 for linear measurements [18]. Comparing the values of the measured fluctuating asymmetry in two different ways, it should be noted that linear measurements give a wider range of asymmetry values and higher asymmetry values compared to determining the fluctuating asymmetry by measuring the areas of the leaf blade halves.

\section{Conclusions}

In the course of the study of the reactivity of morphological parameters of leaf blades of $B$. pendula, a significant decrease in foliar parameters and modification of indicators of variability of morphological features under the influence of factors of ash and slag dumps of Burshtyn TPP were recorded. The most variable feature in both areas was the distance between the first and second vein. A high rate of variability under stress is characterized by the length of the second vein and the angle between the central and second vein. These foliar parameters can be used in bioindication studies as highly sensitive markers of the state of the environment.

The elongation coefficient does not differ in the two studied areas and is approximately 1.3. The coefficient of shape on the territory of ash and slag dumps of Burshtyn TPP is 0.84 and reflects the change in the shape of the leaf blade under the influence of man-made load factors and can be use as bioindication marker. There is a decrease in the area of the assimilation apparatus with a simultaneous increase on the level of necrotic lesions $(14.1 \%$ of the assimilation surface) under the conditions of growth on the ash and slag dumps of Burshtyn TPP. There is high level of fluctuating asymmetry $(0,052)$ under the condition of man-made environmental factors of Burshtyn TPP.

\section{References}

1. Voron, V.P. (2011). Trees and shrubs of Ukraine: an atlas for practical classes on dendrology. A New Word.

2. Barabash, O.V., Lozova, T.M., \& Kozlova, T.A. (2018). Assessment of antropogenic influence intensity by the level of fluctuation asymmetry of morphological structures. Biology and Ecology, 4, 66-72. https://doi.org/10.5281/zenodo.1318179

3. Ganzha, D. (2012). Morphological response of poplar leaves in a variety conditions of anthropogenic load. Visnyk of the Lviv University Series Biology, 60, 163-170.

4. Zoryna, A.A. (2012). Methods of statistical analysis of fluctuating asymmetry. Principles of the Ecology, 3(3), 23-45. https://doi.org/10.15393/j1.art.2012.1461

5. Zverev, V., Lama, A., \& Kozlov, M. (2018). Fluctuating asymmetry of birch leaves did not increase with pollution and drought stress in a controlled experiment. Ecolological Indicators, 84, 283-289. https://doi.org/10.1016/j.ecolind.2017.08.058 
6. Ivanchenko, O.E., \& Bessonova, V.P. (2016). Indication of the condition of woody plants in the parks of Dnipropetrovsk by morphophysiological indicators. Visnyk of Dnipropetrovsk University, Biology, Ecology, 26(1), 109-118.

7. Krupey, K., Obruch, K., \& Mihailichenko, A. (2019). Phytoindication of the environmental conditions by the degree of leaves damage of Betula pendula Roth. Problems of Bioindications and Ecolology, 24(2), 66-74. https://doi.org/10.26661/2312$\underline{2056 / 2019-24 / 2-06}$

8. Leung, B., Forbes, M.R., \& Houle, D. (2000). Fluctuating asymmetry as a bioindicator of stress: comparing efficacy of analyses involving multiple traits. The American Naturalist, 155(1), 101 - 115. https://doi.org/10.1086/303298

9. Lutsyshyn, O.G., Radchenko, V.G., Palapa N.V., \& others. (2010). Macromorphological changes of reaction-response of plant organisms of tree street plantings of Kyiv metropolis at stress level of technogenic pollution. Reports of the National Academy of Sciences of Ukraine, 6, 180-187.

10. Mylen'ka, M.M. (2009). Bioindication assessment of the ecological condition of the Burshtyn urban ecosystem. Doctoral dissertation, Dnipropetrovsk National University named after O. Gonchar.

11. Nesplyak, O.S. (2011). Ecological peculiarities of asheslag dumps' flora and vegetation of Burshtynska thermal electric power station and their using in recultivation. Doctoral dissertation, Dnipropetrovsk National University named after O. Gonchar.

12. Pliatsuk, D.L. (2015). Integrated express-evaluation of air quality under changing industrial infrastructure of the region. Eastern-European Journal of Enterprise Technologies, 3(6), 58-63. https://doi.org/10.15587/1729-4061.2015.43753

13. Pryimak, O.P., Pugach, A.N. (2012). Effect of motor vehicle emission on assimilative apparatus of decorative ornamental plants. Regulatory Mechanisms in Biosystems, 3(1), 118-124. https://doi.org/10.15421/021217

14. Pryimak, O.P. (2012). Phytotoxic effect of $\mathrm{SO}_{2}, \mathrm{NO}_{2}$ and lead ions on the vegetative organs of decorative plants. Biosystems Diversity, 20(1), 78-83. https://doi.org/10.15421/011211

15. Sandner, T.M., Zverev, V., Kozlov, M.V. (2019). Can the use of landmarks improve the suitability of fluctuating asymmetry in plant leaves as an indicator of stress. Ecolological indicators, 97, 457-465. https://doi.org/10.1016/j.ecolind.2018.10.038

16. Skliarenko, A.V. (2019). Assessing the impact of industrial conditions on the level of fluctuating asymmetry of the Betula pendula leaf blade in the city of Zaporizhzhya. Scientific Bulletin of UNFU, 29(6), 54-57. https://doi.org/10.15421/40290611

17. Semak, U.Y. (2020). Variation in leaf morphological traits of Populus tremula L. under the conditions of technogenic load. Visnyk of the Lviv University, Series Biology, 82, 121-128. http://dx.doi.org/10.30970/vlubs.2020.82.10

18. Semak, U.Y. (2020). The influence of technologically transformed environment factors on the level of fluctuation asymmetry of tree plants leaves blades. Scientific Bulletin of the Uzhhorod University. Series Biology, 48, 28-33. https://doi.org/10.24144/1998$\underline{6475.2020 .48 .28-33}$

19. Yusypiva, T., Miasoid, H. (2019). The state of bio-ecological characteristics of the oneyear shoot of Robinia pseudoacacia L. under the conditions of industrial pollution. Ekologia, 38(3), 240-252. https://doi.org/10.2478/eko-2019-0019

20. Yusypiva, T.I., Zadesenets, A.O., Karas, A.V. (2019). Variability of morphometric characteristics of Betula pendula lamina under technogenic conditions of Dnipro city. Ecology and Noospherology, 30(2), 68-73. https://doi.org/10.15421/031912 